\author{
AMÁN ROSALES RODRÍGUEZ \\ Universidad Adam Mickiewicz de Poznań / Universidad de Łódź \\ arosales@amu.edu.pl
}

\title{
HIBRIDISMO CULTURAL Y LITERATURA EN EL CONTEXTO DE UNA "POÉTICA DE LA RELACIÓN"
}

\begin{abstract}
Amán Rosales Rodríguez, Hibridismo cultural y literatura en el contexto de una "poética de la relación" [Cultural hibridism and literature in the context of a "poetics of relation"], Studia Romanica Posnaniensia, Adam Mickiewicz University Press, Poznań, vol. XL/2: 2013, pp. 119-131. ISBN 978-83232-2597-3. ISSN 0137-2475. eISSN 2084-4158.

Adopting as main conceptual framework the proposals of the important thinker and poet from Martinica, Édouard Glissant (1928-2011), about a "poetics of relation", the article considers the way in which a significant part of the contemporary Spanish speaking literary creation - precisely in virtue of its hybrid or mixed cultural nature - is a good example of the fertility of Glissant's "poetics of relation" in which other key concepts of Glissant's theoretical point of view, like the "archipelagic thought" and the "Whole-World", are included. Thus, the convergence between certain theoretical perspectives rooted in the francophone Caribbean context and similar intuitions literary developed in the Hispanic American region is highlighted.
\end{abstract}

Keyw ords: "Poetics of Relation", Cultural Hibridism, Creolization, Nomadism

Aunque su creación literaria surgió y se desarrolló en el ámbito francófono, el pensador y poeta martiniqués Édouard Glissant (1928-2911) siempre fue consciente de la necesidad de concebir de forma unitaria la experiencia histórica caribeña con la hispanoamericana. Unidad que en virtud de su pluralidad lingüística destaca por la riqueza de sus variadísimos elementos constitutivos y posibilidades de expresión artística. Si bien esta riqueza sobresale en todos los ámbitos de la creación cultural del subcontinente americano, en los últimos lustros ha conocido un renacimiento especial en el campo literario gracias a la tenaz labor de un grupo numeroso de escritores que trabajan desde la experiencia de lo diaspórico y la desterritorialización, el nomadismo y el desplazamiento.

Así, asumiendo de forma seguramente inconsciente una de las ideas centrales de la "poética de la relación" impulsada por Glissant, la obra de muchos escritores contemporáneos, concebida y producida fuera del contexto hispanoparlante, comprueba 
con productos concretos la paulatina consolidación mundial de fenómenos como la creolización ${ }^{1}$ y el hibridismo literario, concebidos por el poeta martiniqués como manifestaciones de una positiva globalización cultural. En la sección siguiente de este trabajo se presentarán las ideas fundamentales de Glissant pertinentes al tema de este trabajo, después se proporcionarán algunos ejemplos recientes de su materialización literaria en el ámbito hispanoparlante.

Hay que recordar, sin embargo, que si bien en los textos literarios por considerar más adelante se percibe el deseo de un mundo unificado por relaciones de creolización, hibridez y mestizaje, se tiene conciencia de que el mundo actual, con su amplia variedad de expresiones de etnocentrismo, racismo y xenofobia, está aún bastante lejos de garantizar el pleno florecimiento de un mundo amparado por la benignidad de una "poética de la relación".

II

Podría decirse que una de las ideas centrales, sino acaso la fundamental que mueve al pensamiento de Glissant, es la convicción de que el mundo contiene una riqueza insospechada de posibilidades de inspiración para la realización humana. El ser humano es una criatura que destaca por una curiosidad insaciable que, pese a toda clase de cortapisas, obstáculos, y censuras, nunca cesa en su afán de conocer, saber y experimentar al máximo posible dicha riqueza. $Y$ aunque es obvio que dicha curiosidad y ansia de saber no deja de entrañar también situaciones negativas y perjudiciales para la misma especie humana y otras especies, el punto de vista de Glissant es básicamente positivo acerca del hecho básico de la exhuberancia cultural.

La abundancia de experiencias que ofrece el mundo se refleja en lo inagotable de la creación artístico-literario que siempre buscará formas interesantes de dar cuenta, mediante la concurrencia de múltiples puntos de vista, de la captación humana, específica y general a la vez, de sus diversos matices. Pero la riqueza de la realidad requiere, para su máximo aprovechamiento y deleite, de la disposición para cederla y compartirla con los otros, tanto con los pertenecientes a un grupo de cercanía como con los que parecieran ser culturalmente distantes, con los más próximos y los más lejanos.

Pues bien, es justo esta dimensión del dejar acontecer y recibir lo culturalmente diverso la que Édouard Glissant ha encapsulado en su sugestiva fórmula del "pensamiento-archipiélago", Con esta expresión, escribe Glissant, se trata de impulsar un "pensamiento del ensayo, de la tentación intuitiva, que se podría adosar a pensamientos continentales que serían sobre todo pensamientos de sistema. A través del pensamiento continental, aún vemos el mundo en bloque, en grueso, o como

${ }^{1}$ Se ha optado por este término como traducción directa de "créolisation", aunque en algunas versiones castellanas, incluso citadas en este trabajo, se utiliza también "criollización". 
un chorro, como una especie de síntesis imponente, tal como cuando observamos sucesivas tomas aéreas de vistas generales de los contornos de los paisajes y de los relieves" (2008a).

Por el contrario, el "pensamiento archipiélago" se complace en la experiencia del detalle, la transitoriedad y lo aparentemente insignificante. En efecto, según Glissant: "A través del pensamiento-archipiélago, podemos conocer indudablemente las más pequeñas piedras de río e imaginar los huecos de agua que éstas cubren, dónde aún se albergan los cangrejos de agua dulce" (2008a). El "pensamiento archipiélago" disfruta de la experimentación intuitiva, por contraste con la inmovilidad de los pensamientos continentales — generados desde el etnocentrismo occidental—, gigantescos contenedores de narrativas totales o sistemas de ideas estimados como (casi) indiscutibles.

Desde el punto de vista de Glissant, el respeto de la diversidad cultural no significa otra cosa que la tolerancia por las diferencias humanas en todas sus modalidades. Se trata de rechazar cualquier intento por universalizar, imponiéndolo, un modo de vida, una lengua, una religión, una filosofía, etc. La diversidad, asevera Glissant en Le Discours antillais (1981), "necesita de la presencia de pueblos no como objetos para ser tragados, sino con la intención de crear una nueva relación. La mismidad requiere un ser fijo, la diversidad establece el llegar a ser" (1989: 98).

En su mayor parte, la historia de occidente ha consistido en repetidos intentos por universalizar a la fuerza, es decir, por imponer como exclusivamente válida una forma de ver y sentir la realidad. Pero contra esa idea de una Historia universal a la que todos los pueblos deben plegarse, se insiste en el presente, como lo hace Glissant, en la necesidad de aceptar una pluralidad híbrida, no excluyente de las múltiples historias que articulan las igualmente plurales identidades mundiales. Como señala un intérprete a propósito del hibridismo cultural: "La estrategia de hibridación apunta a la potencialización de la diferencia y no a su reducción, asimilación, adaptación, en un primer momento. En un segundo momento, la estrategia de hibridación conduce a un «reconocimiento de la diferencia», esto es, a la posibilidad de negociar identidades diferentes en un tercer espacio" (de Toro, 2005: 3).

El pensamiento continental o tradicional produce imaginarios que resultan monolíticos y por lo tanto excluyentes de formas ancestrales, supuestamente no asimilables - dentro del bloque de la homogeneización cultural—, de la experiencia humana. Por el contrario, argumenta Glissant, la mentalidad del archipiélago apunta por la variedad de experiencias sin prejuzgar su procedencia: más bien se complace y solaza, como ya se dijo, en el detalle, la minucia y lo intrascendente. Por eso el proceso de creolización, tal y como lo entiende Glissant, se desliga de la idea de "esencia" o "filiación única" que está a la base de imaginarios nacionalistas, excluyentes de la variedad y fundadores de jerarquías sociales basadas en ideas como las de "pureza de sangre". Todo lo contrario, como señala una autora sobre la interpretación de Glissant, la "creolización es la imposibilidad de lineajes legítimos, orígenes raciales puros, o afiliaciones culturales reificadas" (Burns, 2009: 102). 
De acuerdo con otra interpretación, C. Sancholuz, el poeta de Martinica, "reclama para su propuesta el «derecho a la opacidad» en oposición a la racionalidad occidental que ha impuesto el principio universal de la transparencia" (2003: 4). La misma autora cita las palabras de Glissant: "La transparencia ya no parece ser el fondo del espejo en que la humanidad occidental reflejaba el mundo a su imagen: al fondo del espejo hay ahora opacidad, un légamo entero depositado por pueblos, légamo fértil pero a decir verdad incierto, inexplorado aun hoy día y la mayoría de las veces negado o insultado, cuya insistente presencia no podemos dejar de advertir" (Sancholuz, 2003: 4).

En este contexto de una poética de lo diverso, distintas experiencias que no son asimilables a una mentalidad cientificista-tecnocrática no son despachadas como meras manifestaciones de irracionalidad y "primitivismo", antes bien son estimadas como expresiones de una creatividad cultural que no discrimina, jerarquizándolas, entre formas del conocimiento-dominio de la naturaleza. En este sentido también, la actividad artística y literaria consigue expresar en palabras, imágenes o sonidos, por ejemplo, cierto tipo de experiencias que enriquecen la autocomprensión humana, pero no mediante la comprobación, la demostración o la prueba, sino mediante la evocación y la sugerencia.

La poética de lo diverso acepta y respeta lo "opaco" de ciertas manifestaciones culturales, reconoce su derecho de presencia y valora su cuota en el incremento de la variedad humana, que, como él mismo Glissant dice, ha de compartirse de forma generosa. Con sus palabras:

En el otro extremo del espectro de estas intuiciones, el pensamiento de la opacidad del mundo [aparece revelando] su luz implícita. La opacidad no se define, ni se comenta. Pero, exigir para todos el derecho a la opacidad, es renunciar a circunscribir las verdades del mundo a la única medida de una sola transparencia, de una sola iluminación, que serían las mías y que yo impondría. La parte de opacidad negociada entre el otro y yo mismo, mutuamente consentida, garantiza su libertad y confirma mi libre albedrío, en una relación de puro compartir (2008a).

Elegir la opacidad significa oponerse a todo intento de comprimir la comunicación humana a lenguajes, se supone, inequívocamente claros. Como ha dicho un comentarista, Glissant apunta a lo fragmentario de la expresión, a la imposibilidad de trazar cuadros completos de una realidad en sí misma signada por la infinitud del detalle y la minucia (cf., sobre este punto, el sugerente trabajo de Ludwig, 1999). Y sin embargo, en la obra de Glissant también se siente una añoranza por la Unidad, pero que no es desde luego la unidad de la homogeneidad, sino de la heterogeneidad.

La unidad de la heterogeneidad no se materializa en algo así como un "universal ideal", en el que se disolverían las diferencias de acuerdo con la dudosa imagen del melting pot multicultural, más bien, dichas particularidades se aceptan e integran dentro de lo que el martiniqués denomina un "universal orgánico", o "Todo-Mundo". El tejido de relaciones que conecta esa totalidad de particularidades ha de fortalecerse, en definitiva, desde una historia común, sobre bases de apertura e intercomunicación que no confundan las diferencias sino que las resalten como ejemplos de la diversidad humana. 
Esa es justamente la forma de pensar que se impulsa desde el "pensamiento del archipiélago". El mundo del archipiélago, el "Todo-Mundo", abre sus estuarios a la navegación errante, no cierra sus puertos al modo de fortalezas creadas para proteger una masa continental temerosa del contacto-contagio allende sus costas seguras. Por eso el redescubrimiento del pasado, la búsqueda de las raíces, como se suele decir a veces, no debe anteponerse a la tarea presente de incorporación de la otredad en todas sus manifestaciones.

Todo lo anterior, que tiene que ver no solo con el contacto entre culturas extranjeras, sino con la voluntad de acercarse a la otredad interna, lo sintetiza en forma elocuente el propio Glissant en una frase extraída de su volumen L'Intention poétique: "El choque de las culturas es una pasión dinámica por las culturas" (2010: 128). La idea también se reitera en un pasaje de su texto "Criollización en el Caribe y en las Américas", en este caso referida al mundo caribeño como puerto abierto al contacto-contagio cultural:

Repito siempre que el mar del Caribe se diferencia del mar Mediterráneo por ser un mar abierto, un mar que difracta, en cambio el Mediterráneo es un mar que concentra. Si las civilizaciones y las grandes religiones monoteístas nacieron en torno de la cuenca del Mediterráneo, esto se debe a la fuerza que tiene ese mar de predisponer el pensamiento del hombre, así sea a través de dramas, guerra y conflictos, a un pensamiento del uno, de la unidad. Por el contrario el mar Caribe es un mar que difracta y lleva a la efervescencia de la diversidad. No es sólo un mar de tránsito y de pasaje, o un mar de encuentro y de implicaciones. Lo que acontece en el Caribe durante tres siglos es literalmente lo siguiente: un encuentro de elementos culturales venidos de horizontes absolutamente diversos y que realmente se creolizan, se imbrican y se confunden uno con el otro para dar nacimiento a algo absolutamente imprevisible, absolutamente nuevo: la realidad criolla (2008b: 9-10).

Como lo expresa la cita anterior, se trata de admitir que con la expansión de la creolización y el "pensamiento del archipiélago" no solo la mera tolerancia —que puede encubrir una aceptación a regañadientes - sino sobre todo el interés por las culturas-otras aumentará aún más. Esto no se da como consecuencia de un condescendiente punto de vista multiculturalista, sino de una genuina actitud de acercamiento-conocimiento de la alteridad que debe ser juzgada, como dice Glissant en la siguiente cita, como culturalmente equivalente en todas sus variedades: "Porque la criollización supone que los elementos culturales colocados unos junto a otros deben ser obligatoriamente «equivalentes en valor» para que esa criollización realmente se efectúe. Eso significa que si en los elementos culturales colocados en relación algunos son inferiorizados con relación a otros, la criollización no se da verdaderamente" (2008b: 12).

La creolización aparece como la consecuencia inmediata de aceptar la perspectiva de la relación como guía de los enlaces entre prácticas culturales y modos de pensar, incluso de aquellos que puedan parecer "superados" desde la mentalidad desacralizada del presente. Frente a estrategias que pretenden inmunizar a la cultura propia de "contaminaciones" con los otros, la creolización apuesta por la multiplicidad y heterogeneidad de los contactos entre las diferentes formas de vida. Así explica la tesis Glissant: 
Contrariamente a estos encierros, la Relación se entiende aquí como la cantidad que resulta de todas las diferencias del mundo, sin que se pueda excluir una sola. No se trata de elevación sino de completud. Su principio sería que se extiende sin fin, hasta la cuantificación absoluta de la totalidad de las diferencias, y que no encuentra justificación en ninguna sublimación, sino que existe absolutamente en esta misma totalidad. Una literatura de la Relación no podría ser 'universal', a pesar de nuestro deseo oculto, sino más bien procesal: sólo tiene lugar cuando cambiamos con el Todo-mundo que, para nosotros, cambia siempre y permanece (2008a).

La "poética de la relación" entiende el contacto entre culturas como una oportunidad de aprender de experiencias pasadas, depositadas, muchas veces, tras incontables vicisitudes, en el patrimonio general de la humanidad. De ahí que la salvaguarda de fenómenos como el arraigo en la magia por parte de algunos de los así llamados "pueblos primitivos", no ha de verse como consecuencia de un intento vano por establecer con ellos lazos "cognitivos", o de "entender" su visión del mundo, sino como un quizá más simple pero al cabo más significativo compromiso con la conservación de la máxima diversidad creativa. Como explica este punto Glissant, la "poética de la relación" se concibe, según frase ya citada, como "la cantidad que resulta de todas las diferencias del mundo, sin que se pueda excluir una sola", de modo que su interés primordial se dirige, para repetirlo una vez más, hacia la promoción de la variedad cultural humana.

El hibridismo cultural es el resultado natural y necesario del "pensamiento del archipiélago" que procura incrementar la heterogeneidad humana en sus múltiples contactos y relaciones. En efecto, según el poeta martiniqués, los efectos negativos de la tendencia hacia una estandarización cultural global, no debe permitir que se subestime el poder de la imaginación para insertar la variedad dentro de una unidad que no tiene porqué ser aniquiladora de la diferencia: "La trama del mundo gana color con todas las particularidades, cuantificadas; con todos los lugares reconocidos. La totalidad no es eso que se ha dado en considerar el ámbito de lo universal. Es la cantidad finita y ya ejecutada del infinito detalle de lo real. Y que, por ser el detalle, no es totalitaria" (2006: 180).

En consonancia con dicha concepción, se debe promover el contacto y el conocimiento con la mayor variedad posible de experiencias cognitivas y estéticas, provenientes de los distintos sectores del planeta. Cualquier exclusión por razones de chauvinismo o etnocentrismo cultural resulta inexcusable en la medida que significa un desaprovechamiento del potencial receptivo del ser humano, de sus formas alternativas de percibir y experimentar la realidad, son formas que, de acuerdo con la "poética de la relación", enriquecen, cada una a su manera, el fondo general de la cultura. Precisamente, elementos como el "pensamiento archipiélago" y la creolización se oponen al empobrecimiento cultural y a la reducción injustificada de la sensibilidad humana, y sugieren, además, un posible rumbo futuro para la experimentación plena de la pluralidad artística.

En qué medida las reflexiones de Glissant pueden ayudar a comprender o a valorar mejor ciertas tendencias recientes en la evolución literaria hispanoamericana, es lo que 
se procurará hacer explícito en la siguiente sección del trabajo. Con tres ejemplos de autores y autoras recientes se ilustrará el modo en que experiencias como el exilio, la diáspora, y la migración en general, han contribuido a hacer de la desterritorialización y el desplazamiento geográfico-cultural elementos fundamentales de la novísima escritura hispanoamericana.

Mediante todo ello se ha afianzado el poder aglutinante de la creolización mundial, visualizada por Glissant en su "poética de la relación". Esta poética encuentra justamente en el fenómeno del desplazamiento geográfico un complemento idóneo. De ahí que, por ejemplo, un estudioso reciente de estos temas considere "el desplazamiento como uno de los componentes centrales de la globalización cultural, como un agente diseminador, como un fenómeno de diasporización" (Toro, 2010: 11).

El estudio de la literatura latinoamericana de los últimos lustros tiende a concederle cada vez más importancia que en el pasado a fenómenos de hibridez y nomadismo literario, de desterritorialización y diasporismo cultural en general. Con esto se resalta el papel desempeñado por los desplazamientos, imaginarios o reales, que efectúan tanto autores como personajes y que han ayudado a configurar todo un universo de relaciones de diversidad humana, étnica, lingüística y religiosa. Todo esto ayuda a comprender las ideas de Glissant en torno a un mundo que, quiérase o no, avanza cada vez más hacia una experiencia de relaciones universales que la literatura revela de forma contundente. Pero esta revelación solo es posible gracias al desplazamiento migratorio, experiencia que constituye, según la interpretación de A. Gnisci, un componente esencial del carácter "aventurero", trashumante, del ser humano.

La migración es la actividad primordial y transhumana de nuestra especie. Primordiales son todas las actividades que han supuesto y fundado un progreso respecto a la condición de la simple evolución biológica: ir de caza, cocinar los alimentos, cubrirse contra el frío, enterrar a los muertos, etc. Transhumanar quiere decir aventurarse, decidiéndolo, liberando y rescindiendo las condiciones de la relación estacionaria. Aventurarse significa ir al encuentro de las cosas que vienen del futuro: quiere decir descubrir que el futuro está más allá de las colinas, siempre más allá (2010: 4-5).

No obstante, hay una diferencia que no puede pasarse por alto, y es que mientras la perspectiva de Glissant expresa un optimismo básico acerca de las posibilidades de ese rico mundo de conexiones interculturales, en muchos de los textos de autores hispanoamericanos que abordan tópicos relativos al nomadismo y el desplazamiento, la percepción de los acontecimientos no suele ser tan esperanzada ni mucho menos $\tan$ optimista.

Es verdad que en varios de los autores y autoras por comentar dentro de poco no siempre se cae en el pesimismo total, pero tampoco parece creerse que el innegable 
hecho de un mundo como el actual, mal que bien geográficamente interrelacionado, por fuerza produzca, ni de lejos, un estrecho entrelazamiento, dígase con cierta vaguedad de tipo "espiritual", entre las personas. Con otras palabras, no se descarta en muchos textos la posibilidad de un mundo conectado por medio de relaciones híbridas, más propensas que las actuales a la solidaridad y la tolerancia, pero su materialización - lo que puede denominarse el sueño de Glissant — parece reservarse para un futuro plagado de obstáculos y por ende no demasiado cercano.

Como ilustración de todo lo anterior, considérese los siguientes tres ejemplos, en ellos resulta determinante el factor idiomático. En la creación de muchos autores y autoras el español aparece con frecuencia, sobre todo para exiliados e inmigrantes, como un elemento estabilizador en medio de condiciones, pasadas y actuales, de incertidumbre y peligro. No obstante, el español tampoco remite en dichos creadores a una obsesión por las raíces y las identidades nacionales. La lengua misma cambia y evoluciona al contacto con otros territorios lingüísticos, exactamente como lo sugiere Glissant en su defensa del hibridismo cultural.

Si se consideran, para empezar, algunos de los textos semi-autobiográficos del escritor chileno, residente desde hace más de tres décadas en Alemania, Omar Saavedra Santis se observarán algunas de las tendencias que he venido indicando como características de una literatura del desplazamiento y la desterritorialización. Notable en especial resulta su escrito "Leer y escribir en la lejanía" (2007) en el que su autor expone con claridad algunas de las aristas más sobresalientes y aspectos más problemáticos ligados al fenómeno del exilio y el nomadismo literario.

Forzado a abandonar su país tras el golpe militar de 1973, Saavedra Santis, con las consabidas dificultades iniciales de adaptación en un ambiente cultural y lingüístico tan diferente del chileno como lo era el alemán de mediados de los años setenta del siglo pasado, logró incorporar a su obra, como elemento articulador de su obra literaria, lo que él mismo denomina una "poética de la lejanía y la otredad".

Por supuesto, dicha poética no tiene que ver con un repertorio delimitado de lugares comunes, de temas o problemas ligados a la experiencia del exilio y la migración, más bien, tal poética se relaciona con algo a la vez profundo e inmediato que solo se revela desde la experiencia concreto-individual de la migración y la desterritorialización. Se trata de una experiencia compartida por miles, sino millones de personas, forzadas a establecerse en ciertos ambientes ajenos en muchos, muchísimos aspectos, a sus vidas pasadas, antes de la migración y el exilio.

La "poética de la lejanía y la otredad" evita los excesos sentimentales a los que se pudiese abocar un examen relativamente apresurado de sus contenidos más obvios por dramáticos. Los evita porque renuncia a reducir las vivencias del exilio y el desplazamiento forzoso a un proceso generalizado y sin perspectivas de rescate de la aculturación y la pérdida de identidad —individual, en este caso- . Aunque sin duda su esencia está determinada por sentimientos de añoranza y melancolía, por lo que se ha perdido irreparablemente durante el camino del exilio, lo .cierto es que tal poética 
no promueve una huída sin más del mundo, fuente de frustraciones, sino la consolidación de una actitud de serenidad y un mantenerse a distancia, al margen de los grandes discursos de centros y periferias culturales.

En el caso de escritores como Saavedra Santis la experiencia del exilio, transfigurada a partir de la mencionada "poética de la lejanía y la otredad", ha contribuido a vigorizar la capacidad de asombro del escritor, como él mismo lo ha admitido, así como a aplacar los impulsos de arrogancia y vanidad a que suelen sucumbir otros artistas que no han pasado por la misma dramática experiencia. Es decir, la poética de la lejanía no es ajena a la nostalgia, pero logra mitigar sus efectos más depresivos mediante la expectativa de la novedad, lo inesperado positivo que suele deparar un ambiente diferente y no enteramente hostil a la creación artístico-literaria.

Así, por ejemplo, como sugiere Saavedra Santis en el texto mencionado, la misma experiencia que suele ser fuente de frustraciones en el caso del manejo de la lengua del exilio, puede transformarse en experiencia de disfrute desde la obligación cotidiana del bilingüismo, oportunidad tanto del disfrute literario como factor de supervivencia diaria: "Nuestra capacidad de asombro ante lo nuevo se vigoriza en la misma medida que se descascara el oropel de nuestra vanidad y arrogancia. Cuando eso ocurre, se abren a nuestra literatura posibilidades inesperadas. Bajo las costras duras de la lejanía y otredad, subyacen fructíferas regiones, donde también es posible sembrar y cosechar" (2007: 7).

Otra escritora contemporánea que ha conocido por varias décadas la experiencia del desplazamiento y el exilio, la colombiana Helena Araújo, reproduce en sus textos algunos de los problemas más complejos vinculados a la relación entre desterritorialización geográfica y exilio interior. Así como en diversas entrevistas la autora ha confesado los sentimientos de desarraigo personal que la llevaron a tratar de romper situaciones personales insostenibles en su país natal, así también en varios de sus relatos, sus personajes luchan por conseguir esa tan esperada redención que se anhela con el alejamiento geográfico.

La narrativa breve de Araújo presenta rasgos muy interesantes que apuntan a situaciones de incomunicación y soledad que, por consustanciales a la naturaleza humana, no se resuelven "simplemente" con la vivencia del exilio y el nomadismo. Tampoco se solucionan necesariamente o de forma inmediata con la aceptación del hibridismo cultural.

Un ejemplo notable de ello lo constituye el relato "Leidenschaft" (2003) - incluido en el volumen Esposa fugada y otros cuentos viajeros, (2009) - en el que el juego de pasión que se desarrolla en el texto en modo alguno comporta una ganancia emocional significativa para la protagonista. La verdad es que las reflexiones del personaje femenino sobre la situación en que está involucrada solo revelan el carácter superficial y fatalmente anodino, frustrante por la incomunicación resultante, en que degeneran muchas veces las relaciones humanas. 
El relato de Araújo sobresale porque va más de allá de meras denuncias de la incomprensión entre los sexos, y se concentra en la exposición, con fino humor negro no exento de compasión y simpatía, de eventos en los que la búsqueda de una aventura y la añoranza de una relación genuina se confunden en una intrincada y laberíntica sucesión de escaramuzas, de persecuciones y huidas — en más de un país — por parte de la protagonista, implicada en una maraña de encuentros en apariencia fortuitos.

En sus reflexiones más autobiográficas sobre el tema del exilio, Araújo se ha referido al cúmulo de contradicciones que tuvo que superar como individuo con intensos intereses intelectuales y literarios en una sociedad patriarcal hostil a concederle a la mujer el espacio debido para sus inquietudes creativas. El exilio interior se convirtió para ella, como para otras autoras de su generación, en una estrategia de desterritorialización espiritual previa y acaso más fundamental que la geográfica. Por eso la autora se refiere con frecuencia al "insilio" como una experiencia aún más dramática que el desplazamiento geográfico.

En varios de sus relatos, Araújo recrea las contradicciones y limitaciones que debe sobrellevar la mujer, en especial la latinoamericana de su generación — surgidas de una atmósfera cultural compartida por los hombres - , y que no pueden superarse sino con la solidaridad y el trabajo conjunto de ambos géneros. No obstante, la necesaria ruptura con modelos sociales y sexuales obsoletos, no siempre logra generar lazos afectivos profundos que garanticen una alternativa real a la frustración inicial.

En otro ejemplo de literatura del desplazamiento y el nomadismo, el escritor boliviano Víctor Montoya recrea en su obra cuentística episodios diversos de su exilio sueco, donde llega después de haber sufrido en su país natal la experiencia de la prisión y la tortura política durante el régimen de Hugo Banzer en los años setenta del pasado siglo. El exilio exterior de Montoya, en forma similar a Saavedra Santis pero a diferencia de Araújo, no se detiene, como es el caso de esta última, en la rememoración de vivencias familiares frustrantes, sino en la de situaciones de aislamiento y desamparo en el lugar del desplazamiento.

En el relato "En el país de las maravillas", por ejemplo, incluido en el volumen Cuentos desde el exilio (2009), Montoya se refiere a las etapas iniciales de su experiencia nórdica, comenzando con el impacto inicial de hallarse en un país donde el invierno significa otra cosa que en la tierra que le vio nacer, "donde el sol ardía en la franela azul del cielo y la tierra calentaba los pies". No obstante, en el caso del protagonista-narrador de la historia, la primera impresión que tiene de su nuevo hogar es fundamentalmente positiva, pues cree, en efecto, haber arribado a un país maravilloso, donde higiene y limpieza, por ejemplo, aparecen como elementos sobreentendidos del entramado social.

La desesperación del refugiado político, que con frecuencia conduce a la amargura y el pesimismo indiscriminados, se metamorfosea en el relato de Montoya en una satisfacción generalizada por lo que le ofrece su nuevo país. Incluso, el agradecimiento del narrador hacia su nuevo anfitrión geográfico se extiende al hecho de que éste le 
ha deparado una nueva relación sentimental con la cual rehacer su vida en el exilio. Al igual que tantos otros autores víctimas de la represión política, Montoya reconoce en su desplazamiento forzado un estímulo radical para su idea de la literatura como vía, a un tiempo, de denuncia social y (re)construcción individual.

La literatura del desplazamiento y la migración adquiere en la obra de Montoya matices conmovedores pero también humorísticos cuando se trata de bosquejar contrastes entre las formas de vida y paisajes bolivianos con las muy disímiles de tierras suecas. El contraste, sin embargo, no siempre se expresa en términos ingenuos, del todo positivos hacia el país de llegada. En otros textos, como en "Asesinato en invierno", su autor se detiene en los aspectos más terribles del exilio relacionados con el odio xenófobo y el asesinato de motivación racista. De nuevo, la desterritorialización comporta oportunidades y riesgos, chances para rehacer una vida o para acabar de destruirla en forma brutal.

El desplazamiento geográfico, espiritual y emocional de los personajes de Montoya coincide con los de otros autores que hacen de sus personajes viajeros en busca de un sentido de arraigo imposible de hallar, por diversos motivos, en sus lugares de origen. Y precisamente, tal vez al final "el lugar de origen" se revela como espurio en la obra de narradores que han atravesado, no indemnes pero que a pesar de todo sí la han sobrevivido, la experiencia traumática del destierro, de la migración forzada. Con su obra creada desde el desplazamiento, los autores arriba mencionados, junto a tantos otros activos en diferentes puntos geográficos no hispanoparlantes, muestran hasta qué punto es posible transformar ciertas vivencias pavorosas en oportunidades que se recrean poéticamente para poder sobrevivir las vicisitudes del desarraigo y la migración forzada.

Si bien el sueño de Glissant de un mundo conectado al modo del archipiélago, aún está lejos de realizarse como experiencia (generalizadamente) compartida, pareciera que la misma dinámica de la globalización genera, como reacción de balance ante sus consecuencias más negativas de aculturación, otros efectos que procuran contrarrestar lo que de otro modo constituirían solo tendencias deshumanizadoras, destructoras de la variedad cultural.

La "poética de la relación" ofrece, como alternativa a relatos esencialistas culturalmente aún muy arraigados, la posibilidad de construir identidades más dinámicas y flexibles, abiertas a influencias, mezclas, negociaciones y traducciones; identidades, en fin, que no se construyan desde el choque sino desde el diálogo en un tercer espacio, neutral, por así decirlo, respecto de imaginarios nacionales autodefensivos. Este último punto señala a la interrelación, que aquí solo se desea dejar indicada, de las ideas de Glissant con los aportes de diversos enfoques poscoloniales. Desde ellos, 
como bien sabe, se cuestiona con el mismo vigor la validez de ciertas dicotomías asentadas sobre concepciones esencialistas de las identidades culturales ${ }^{2}$.

Después de considerar algunas muestras de una creación literaria hispanoamericana producida allende las fronteras nacionales, se puede constatar un anhelo de unidad en la diversidad muy similar al que impulsa la "poética de la relación" de Glissant. Y aunque esta sensibilidad está también algunas veces teñida de desesperanza y frustración, no faltan pruebas de que los impulsos solidarios no se han perdido de forma irremisible. La añoranza que aún se conserva - si bien ya no por una mítica identidad perdida o transfigurada sino simplemente por el hogar natal, el lugar feliz de la infancia, por ejemplo - no tiene porqué conducir al derrotismo ni a claudicar en el pesimismo generalizado.

La propuesta a favor de la creolización, del contagio e hibridación cultural, se fundamenta en la capacidad humana de absorber, procesar y retrasmitir conocimientos, destrezas y saberes de variada índole, aprovechándolos para la obtención de fines como el crecimiento personal, la justicia social y la solidaridad humana. Porque, aún en el caso de situaciones no enteramente favorables para la concreción de tales metas, como en diversas formas de exilio, migración y desterritorialización forzada, el ser humano logra cosechar de ellas, con frecuencia, algún fruto positivo susceptible de socialización. El deseo de Glissant es que, en beneficio de un urgente conocimiento intercultural, se explote al máximo dicha capacidad para el contacto y el intercambio dinámico de experiencias.

\section{BIBLIOGRAFÍA}

BuRns, Lorna (2009): "Becoming post-colonial, becoming-Caribbean: Edouard Glissant and the poetics of creolizatiuon", Textual Practice 23 (1): 99-117. URL: <http://www.academia. edu/217812/Becoming-Postcolonial_Becoming-Caribbean_Edouard_Glissant_and_the_Poetics_of_Creolization> (consulta: 10.10.2012).

Glissant, Edouard (2010): Poetic Intention, trans. N. Stephens. Callicoon, N. Y.: Nightboat Books. - (2008a): "Pensamientos del Archipiélago, pensamientos del Continente", trad. Ana-Rosa Telado, Revista El Aleph. URL: <http://www.revistaaleph.com.co/index.php/component/k2/item/208pensamientos-del-archipielago-pensamientos-del-continente> (consulta: 10.10.2012). — (2008b): "Criollización en el Caribe y en las Américas", Poligramas, diciembre 2008: 11-18.

${ }^{2}$ Con mucha frecuencia, como señala una autora: "El campo semántico del exilio —-desarraigo', 'pérdida', 'no-pertenencia', 'alienación' - sugiere que, según las normas, uno está enraizado en un territorio geográfico, lingüístico y cultural al que pertenece y por lo cual se distingue de otros sujetos culturales. Presupone que esta pertenencia cultural garantiza al individuo una identidad propia, autentica, estable y le da consistencia y seguridad. Las oposiciones binarias entre origen y pérdida del origen, pertenencia y desarraigo, autenticidad y desalineación - muy frecuentes en textos que tratan del exilio - reflejan un concepto identitario (personal y cultural) que es monovalente y que todavía no ha descubierto al 'extranjero en sí mismo'. En consecuencia, el contacto con el sujeto cultural 'otro' se percibe como enfrentamiento de dos entidades con carácter definitivo y fijo” (Mertz-Baumgartner, 2005: 15). 
- (2006): Tratado del Todo-Mundo, trad. M.T. Gallego Urrutia. Barcelona: El Cobre.

- (1997): Poetics of Relation, trans. B. Wing. Ann Arbor: The University of Michigan Press.

- (1989): Caribbean Discourse. Selected Essays, trans. J.M. Dash. Charlottesville: The University of Virginia Press.

GNISCI, Armando (2010): "Escrituras migrantes", trad. A. Lozano de la Pola, Extravío. Revista electrónica de literatura comparada, núm. 5. Universitat de València, 1-6. URL: <http://www. uv.es/extravio> (consulta: 10.10.2012).

Ludwig, Ralph (1999): “Frankokaribische Literatur: Etappen und Perspektiven”. In: H.-J. LüsERBRINK, J. RiEz [eds.], Frankophone Literaturen außerhalb Europas. Frankfurt am Main: Verlag für interkulturelle Kommunikation. URL: <http://www.potomitan.info/articles/karibilite1.pdf $>$ (consulta: 10.10.2012).

Mertz-Baumgartner, Birgit (2005): “Introducción: Experiencias del exilio y procesos de transculturación. ¿Dos percepciones de una misma realidad?”. In: B. Mertz-BAumgartner, Erna PfEIFFER [eds.], Aves de paso: autores latinoamericanos entre exilio y transculturación (19702002). Madrid: Iberoamericana, 11-18.

Montoya, Víctor (2010): "En el país de las maravillas". In: Esther ANDRADI [comp.], Vivir en otra lengua. Literatura latinoamericana escrita en Europa. Madrid: Alcalá.

SAAVEdRa SANTIS, Omar (2007): "Leer y escribir en la lejanía", URL: <http://www.cervantes.de/ nueva/de/biblioteca/archivo-digital/pdfs/Leer\%20y\%20escribir\%20\%28Instituto\%20Cervantes\%20-\%2023\%20abril\%202007\%29.pdf> (consulta: 10.10.2012).

SANChOluz, Carolina (2003): "La construcción del área cultural caribeña: los aportes de Édouard Glissant a partir de Le discours antillais", Orbis Tertius, 2002-2003, VIII (9): 1-9. URL: $<$ http://www.orbistertius.unlp.edu.ar/numeros/orbis-tertius-9/articulos/07-sancholuz.pdf $>$ (consulta: 10.10.2012),

Toro, Alfonso de (2005): "Pasajes - Heterotopías - Transculturalidad: estrategias de hibridación en las literaturas latino/americanas: un acercamiento teórico". URL: <http://www.unileipzig. de/ detoro/sonstiges/Pasajes_Heterotopias_Transculturalidad.pdf $>$ (consulta: 10.10.2012).

Toro, Fernando de (2010): "El desplazamiento de la literatura, la literatura del desplazamiento y la problemática de la identidad" [artículo en línea]. Extravio. Revista electrónica de literatura comparada núm.5. Universitat de València. URL: <http://www.uv.es/extravio> (consulta: 10.10.2012). 